Revue des patrimoines

$34 \mid 2018$

Lieux de pouvoirs. Architectures administratives dans la France contemporaine, 1945-2013. Avant/Après la décentralisation

\title{
Nicolas Chaudun (dir.). Balard. Paris : Tallandier- Ministère de la Défense, 2015, 164 p.
}

\section{Emmanuel Pénicaut}

\section{(2) OpenEdition}

Journals

Édition électronique

URL : http://journals.openedition.org/insitu/15863

DOI : 10.4000/insitu. 15863

ISSN : $1630-7305$

Éditeur

Ministère de la culture

Référence électronique

Emmanuel Pénicaut, « Nicolas Chaudun (dir.). Balard. Paris : Tallandier-Ministère de la Défense, 2015

164 p. », In Situ [En ligne], 34 | 2018, mis en ligne le 27 avril 2018, consulté le 30 avril 2019. URL http://journals.openedition.org/insitu/15863 ; DOI : 10.4000/insitu.15863

Ce document a été généré automatiquement le 30 avril 2019.

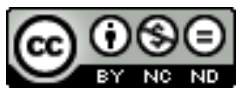

In Situ Revues des patrimoines est mis à disposition selon les termes de la licence Creative Commons Attribution - Pas d'Utilisation Commerciale - Pas de Modification 4.0 International. 
Nicolas Chaudun (dir.). Balard. Paris : Tallandier-Ministère de la Défense, 2015, 164 p.

Emmanuel Pénicaut

Figure 1

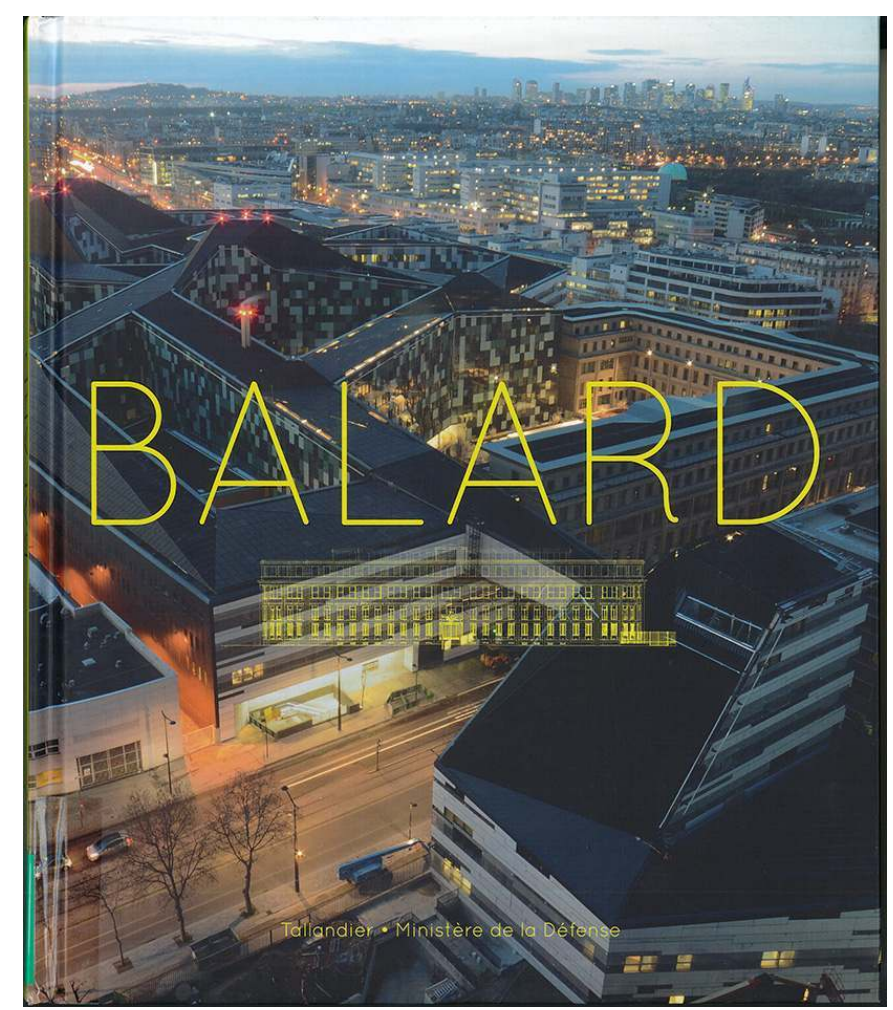

Page de couverture : Nicolas Chaudun (dir.). Balard. Paris : Tallandier-Ministère de la Défense, 2015. 
1 Inauguré en 2015, le site de «Balard»- du nom du chimiste français du xix ${ }^{\mathrm{e}}$ siècle auxquelles furent dédiées, en 1895-1896, la rue et la place voisines ${ }^{1}-$, qui regroupe en un lieu unique les grands états-majors du ministère de la Défense et son administration, méritait un ouvrage pour le faire connaître. En effet, cette friche aux marges de la plaine de Grenelle, qui n'entra dans l'histoire parisienne que tardivement, ne s'impose pas dès l'abord comme un site militaire chargé d'histoire, et son emprise, tout en courbe et cernée par les boulevards des maréchaux et le périphérique, n'en fait pas une destination de premier plan. Quoique brève, l'histoire du lieu n'est pas dénuée d'intérêt. C'est celle de ces confins de la ville, évoqués par N.Chaudun (p.14-51), témoins silencieux de la croissance d'une capitale que rien n'arrête: ainsi la chasse céda-t-elle la place aux cultures vivrières, puis celles-ci à la proto-industrie, tandis que se dressait, à partir de 1841, l'ombre des fortifications de Thiers. Quoique inutiles, ces fortifications illustraient la place de l'armée dans la vie quotidienne de Paris : entre la guerre extérieure et les menaces intérieures, l'exécutif $d u x x^{\mathrm{e}}$ siècle, qu'il fût monarchique, impérial ou républicain, savait la nécessité de défendre et de surveiller la capitale, et donc de prêter l'oreille aux exigences incessantes de l'armée. Celle-ci occupait des lieux de prestige - les Invalides, l'École militaire, l'îlot Saint-Germain, le château de Vincennes - ainsi qu'une quantité innombrable de casernes intra-muros. Mais elle réclamait aussi du terrain non bâti pour les manœuvres et les expérimentations : le bois de Vincennes, transformé en terrain d'artillerie depuis la Révolution, en avait fait les frais. En 1889, profitant du souhait de la Ville de Paris d'obtenir la propriété du Champ-de-Mars, le ministère de la Guerre négocia en contrepartie les 63 hectares de terrain de la plaine d'Issy, qui furent dans un premier temps confiés au Génie. C'est alors, seulement, que le terrain trouva son identité : car la plaine se révéla bientôt un terrain idéal pour accueillir non seulement les dirigeables mais aussi les premiers essais de l'aviation française, civile puis militaire. Les records s'accumulèrent avec le nouveau siècle, et attirèrent les industriels : le champ de manœuvres d'Issy devint, en quelques années, le berceau mondial de l'aviation. S. Texier décrit ensuite (p.53-82) les transformations de l'après-guerre, en les replaçant dans l'histoire de l'urbanisme parisien : la démolition des «fortifs ", puis la construction de l'École nationale supérieure de l'aéronautique à partir de 1928, sur les plans de Léon Tissier, bientôt suivie des bâtiments du tout récent ministère de l'Air.

2 À la dimension aéronautique du site s'ajouta celle des constructions navales, à l'extrémité ouest de l'emprise, donnant déjà au lieu son caractère interarmées : dès 1906, un premier bassin d'essai des carènes fut inauguré, bientôt complété par d'autres sous l'autorité de l'agence Perret, qui fit du site, entre 1928 et 1952, un véritable centre technique. En subsiste le bâtiment de direction, «œuvre majeure et décisive dans le parcours de Perret» (p.69), protégé au titre des monuments historiques en 1965. M.-C. Villatoux (p. 85-105) reprend le fil de l'histoire aéronautique du lieu, en évoquant les grandes heures de la «BA 117 », du nom de l'unité de l'armée de l'Air chargée du soutien du site. Après la Deuxième Guerre mondiale, l'aviation militaire prit un nouvel essor sous l'impulsion du général Martial Valin ; cependant, les progrès techniques et l'urbanisation rendirent le champ de manœuvres définitivement impropre aux avions, et celui-ci fut réduit puis réservé aux hélicoptères à partir des années 1950. L'heure n'était plus aux entraînements ni aux records mais à la création dans le sud de Paris d'un complexe à la fois militaire et industriel, mêlant institutions publiques (CEA, École polytechnique) et semi-publiques ou privées (SNECMA, Aérospatiale, Dassault), avec pour " point focal » (p.95) la Cité de l'air. Celle-ci, quoique divisée par le percement du boulevard 
périphérique à partir de 1958, se transforma en conséquence. Mais les nombreux bâtiments qui y poussèrent témoignaient plus des besoins successifs - ou des rivalités des grands services du ministère que d'un plan programmé. En 1968, l'architecte des Bâtiments civils et Palais nationaux Pierre Large pouvait écrire que les bâtiments de la Cité "n'ont aucune valeur architecturale », et que son remodelage et sa remise en ordre "apparaissent une nécessité évidente» (p. 101). Les nouvelles constructions lancées alors, parmi lesquels la "tour F », livrée en 1971, puis la fameuse "tour A », de section elliptique, achevée en 1978, ne contribuèrent guère à l'unité architecturale du site, qui accueillit désormais la DGA aux côtés de la Marine et de l'armée de l'Air. On devine, même si les auteurs ne le soulignent pas, que l'organisation de la Cité de l'air était loin d'être la priorité du ministère; celui-ci, contraint par la politique de décentralisation à céder nombre d'emprises parisiennes, réussit cependant à le conserver dans son giron. La dernière contribution de l'ouvrage, due à Sophie Humann (p. 111-144), évoque le choix du site de Balard, en 2007, pour le regroupement des services centraux et des états-majors du ministère, et décrit ensuite " le plus grand chantier de France » (p. 136) lancé en 2012 et achevé en 2015. La construction du nouveau bâtiment par l'architecte Nicolas Michelin, qui recouvre entièrement la place occupée par le service des constructions navales, la rénovation de la parcelle ancienne de la Cité de l'air et des bâtiments historiques de Perret et Tissier sont exposées et illustrées.

Livre de mémoire autant que d'histoire, servi par une iconographie abondante et variée, Balard offre une synthèse très utile de l'histoire de cette parcelle jusqu'ici délaissée par l'historiographie des emprises militaires. On regrettera quelques détails de forme, tels que l'absence d'une chronologie et d'un état des sources, et aussi, peut-être, le manque de développements sur les circonstances du basculement qui conduisit en 2007 à décider d'un site unique pour des états-majors jusqu'alors distincts, et à transformer l'emprise de Balard, d'une base aérienne et d'un centre d'essais, en « cœur névralgique de la Défense française " (p. 144). La préface de J.-Y.Le Drian, ministre de la Défense, évoque l'achèvement « d'un mouvement d'unification pensé dès la fin du XIX siècle et accéléré par le général de Gaulle »; comme en écho, l'architecte Nicolas Michelin écrit que sa principale difficulté, pour dessiner le bâtiment, fut «de savoir à quoi ressemble un ministère de la Défense » (p. 123). La substitution du pluriel «des Armées » au terme «Défense » dans l'appellation du ministère, voulue en 2017 par le président de la République, laisse penser que l'identité de l'administration militaire est une question qui ne se réduit pas à sa politique immobilière, même si celle-ci demeure un excellent prisme d'observation.

\section{NOTES}

1. - Dans le quartier de Javel, $15^{\mathrm{e}}$ arrt. 


\section{AUTEUR}

\section{EMMANUEL PÉNICAUT}

Adjoint au directeur de la médiathèque de l'Architecture et du Patrimoine emmanuel.penicaut@culture.gouv.fr 